\title{
Borges: fervor de Dante
}

\section{Francisco J. Rodríguez Risquete}

Universitat de Girona

\section{Resumen}

Ya son más de una docena los estudios dedicados a la asimilación de Dante en la obra de Borges, pero la dispersión bibliográfica y la carencia de una edición crítica de los textos borgesianos pueden suponer un obstáculo serio para quien pretenda estudiar este aspecto de forma sistemática. Por ello, en este artículo se ofrece una síntesis de los problemas que entraña la presencia de Dante en Borges (cronología de su presencia, tendencias de la crítica y significado de Dante en la poética del escritor argentino). También se ofrece un corpus, ordenado y completo, de las menciones de Dante en las narraciones, ensayos y poemas del bonaerense, que incluye los ensayos que este dedicó a la Comedia, los recuerdos autobiográficos que le conciernen, las menciones generales y precisas, y los comentaristas de Dante que citó a lo largo de sus textos.

Palabras clave: Borges, Dante, Divina Comedia, corpus.

\section{Abstract}

There are already a good deal of studies given over to Dante's inclusion in the works of Borges, yet a dispersed bibliography and the lack of a critical edition of Borgian texts may pose a serious obstacle to anyone trying to study this aspect in a systematic fashion. For this reason, this article offers a synthesis of the problems that Dante's presence in Borges involves (the chronology of his appearance, the trends of the critics and the meaning of Dante in the poetics of the Argentine writer). It also offers a corpus, both ordered and complete, of references to Dante in the narrations, essays and poems of this native of Buenos Aires, including the essays he dedicated to la Commedia, the autobiographical memories concerning the work, general and concrete references, as well as the Dante commentators he cites throughout his texts.

Key words: Borges, Dante, The Divine Comedy, corpus.

Los estudios que la crítica ha dedicado a la presencia de Dante en Borges empiezan a ser numerosos, y sus logros han sido, en muchos casos, determinantes para entender la concepción que Borges tenía de la literatura. Sin embargo, se viene echando en falta una visión panorámica que ponga las bases de un estudio sis- 
temático de la Comedia en la obra de Borges. Por ello, este artículo persigue tres objetivos: en primer lugar, intenta poner orden en la bibliografía que la crítica ha consagrado al asunto; en segundo lugar, quiere establecer mínimamente las fechas en las que Borges accedió y utilizó a Dante; en tercer lugar, se propone confeccionar un corpus completo (hasta donde sea posible) de las menciones de la Comedia en artículos, narraciones y poemas del escritor argentino ${ }^{1}$.

Con pocos autores se mostró Borges tan elogioso como con Dante. De algún modo, el escritor argentino dedicó buena parte de su vida a devolverle a la Comedia la pasión y el goce que, como lector, había recibido de ella. Una buena muestra de cuanto decimos es una conferencia que dictó en 1961 . Durante la charla, el argentino entronizó al italiano como «el poeta arquetípico de Italia y, por ende, de todo Occidente»; más aún: Dante es, «tal vez, el primer poeta del mundo» (n. 9). Estos elogios, en boca de Borges, no son exagerados, porque buena parte de su obra contribuye a justificarlos.

¿Qué aspectos de la Comedia inclinaron a Borges a formular este juicio? Mejor aún: ¿qué función cumple Dante en su obra crítica, en su narrativa y en su poesía? A mi entender, Borges se sirve de la Divina Comedia de tres modos distintos. En primer lugar, los versos del italiano son para Borges una dilatada cantera de ejemplos adecuados a sus teorías. Los investigadores borgesianos, y aun muchos de sus lectores, saben de sobras que el escritor argentino solía obsesionarse con un cierto número de citas de distintos autores, y que tales citas reaparecen en sus obras una y otra vez. Esas referencias, que a menudo sirven a intereses mnemotécnicos, pueden consistir en versos, estrofas completas, episodios o aspectos determinados dentro del conjunto de una obra,

1. A lo largo del corpus, que ocupa la mayor parte de este trabajo, he optado por no remitir a los textos de Borges por edición y página. La explicación es sencilla. En los estudios sobre literatura contemporánea en general, y en los dedicados a Borges en particular, es poco común que los investigadores remitan a ediciones de referencia. Por el contrario, cada cual, conforme a sus posibilidades, cita según la edición que tiene más a mano. Fruto de ello, las remisiones a un mismo texto suelen variar de un estudio a otro, dependiendo de la paginación de la edición o reedición con la que cada investigador haya trabajado. Esta circunstancia hace que tales remisiones sean poco útiles, porque o bien uno tiene a su alcance todas las ediciones de la obra en cuestión, o bien se ve obligado a buscar página por página en la suya, y en tal caso de poco le habrá servido la cita de partida. La edición de referencia, en el caso de Borges, debería ser las Obras completas de Emecé, pero es notorio que sus volúmenes sufren una metamorfosis constante y la paginación de un año no suele coincidir con la de los siguientes. En su defecto, las ediciones de referencia deberían ser las editiones principes, como sucede con el Quijote de Cervantes, pero es impensable que la mayoría de investigadores pueda trabajar con primeras ediciones de las obras de Borges, y también lo es que las ediciones modernas remitan algún día a la paginación de las primeras. Por todo ello, creo que, en el caso de Borges, se hace necesario un sistema universal de citación útil y realista. En este artículo, adopto una convención tan arbitraria como cualquier otra: en cada capítulo o texto sin división en capítulos, numero los párrafos (precedidos del símbolo $\$$ ) sin tener en cuenta los diálogos. O dicho de otro modo: cada sangría del texto es el inicio de un párrafo, salvo aquéllas que introducen la intervención en estilo directo de un personaje. Desde luego, el primer párrafo también entra en el cómputo aunque no está sangrado. Por otro lado, a lo largo de este artículo, las cifras en negrita remiten a la ordenación del corpus. 
y sirven a Borges para ilustrar sus argumentos. Como veremos a continuación, Dante también pobló la memoria de Borges, hasta el punto de que muchos de sus versos se repiten como una obsesión a lo largo y ancho de sus páginas. Para estudiar como conviene este instrumento mnemotécnico, tal vez el primer paso debería consistir en fechar esas obsesiones con la mayor precisión posible. Como es bien sabido, en la memoria de Borges, y en especial después de su ceguera, hay recuerdos que resisten al viento del tiempo, mientras que otros se desvanecen para siempre. Dante quizás nos ofrezca los mejores ejemplos de ello, y a la cronología de su presencia en la memoria de Borges dedicaré un apartado más adelante.

En segundo lugar, la obra de Dante funciona, en algunos textos, como un estímulo para evocar los temas preferidos del autor argentino. Se trata del proceso contrario al que acabo de esbozar. Borges, por caso, tropieza en una de sus muchas relecturas de la Comedia con un verso que, en su memoria, activa por asociación el recuerdo de otros textos y temas. Es lo que sucede en las poesías y las prosas que nacen de la inspiración de un verso del poeta italiano. Pensemos, a modo de ejemplo, en «Infierno, I, 32» (n. 71), «Infierno, V, 129» (n. 78), «Poema conjetural» (n. 87), «La otra muerte» (n. 91) y «Paradiso, XXXI, 108». En estos casos, el texto de Dante no se limita a ilustrar un tema, pero tampoco es el asunto principal del texto. En los ejemplos aducidos, el texto de Dante es más bien un punto de partida desde el cual se eleva una reflexión de tintes trascendentales. Los versos de la Comedia, en tales casos, han estimulado la poderosa inteligencia de Borges porque le han recordado los temas que más le obsesionan.

Finalmente, la Divina Comedia funciona como un símbolo, más allá de sus contenidos y de sus pormenores. Para apreciar mejor este extremo, no estará de más que recordemos la afirmación, recién citada, de la conferencia que impartió Borges en 1961: Dante es, tal vez, «el poeta arquetípico de Occidente». El adjetivo, como sucede a menudo en boca del escritor argentino, no es inocente. Dante es el arquetipo del mundo occidental porque, mejor que cualquier otro clásico, su obra magna resume y condensa las formas ideales de una cultura y una civilización. "La obra que perdura es siempre capaz de una infinita y plástica ambigüedad; es todo para todos, como el Apóstol; es un espejo que declara los rasgos del lector y es también un mapa del mundo», decía Borges en «El primer Wells», $\$ 4$ (Otras inquisiciones). La Comedia, como todo libro verdaderamente clásico (véase el n. 28), ha alcanzado su estatus según sentencia del tiempo. Ha resistido, más allá de las generaciones y de las lenguas, todas las lecturas y todas las interpretaciones. Por este motivo, Dante deviene un símbolo de la literatura. Los siglos lo han consagrado en la memoria compartida de la humanidad. Pero para ser aceptados por todas las generaciones, para ser «todo para todos», la Comedia y Shakespeare y Homero han tenido que renunciar a una identidad ceñida y restrictiva. Un clásico, en las definiciones que Borges le prodigó, es siempre una obra que sacrifica su perfil concreto para ser ambigua e infinita. Borges, en su tarea de dantista, llevará esta premisa hasta sus últimas consecuencias, porque en sus manos la Comedia no será tan solo un producto de Dante, sino la proyección mental de sus lectores. 
A Borges, además, le gusta mencionar la Comedia como símbolo, porque, en tanto que clásico, es un vínculo que lo une a cualquier lector, sea cual sea su patria o su época. En el prólogo que compuso para los Mystical Works de Swedenborg, Borges advertía que las palabras y los símbolos son recuerdos compartidos por autor y lector. Como se sabe, esta cuestión es crucial en el pensamiento lingüístico de Borges. La comunicación solo es posible cuando las dos partes implicadas disponen de una memoria compartida, que se actualiza mediante las palabras. Pero ya que la memoria siempre difiere de un hombre a otro, la comunicación resultará precaria en todos los casos. La Comedia, como todo libro clásico, también es un recuerdo compartido por los lectores, y por ello es una herramienta útil para la comunicación. Pero, dada su ambigüedad, dada la indefinición a la que se ha tenido que someter para llegar a clásica, también ese recuerdo diferirá de un lector a otro. El único valor transmisible de la Comedia, por tanto, será el de su carácter proteico, el de su dimensión universal. Tras las numerosas citas que Borges hace de Dante no se oculta únicamente una pasión muchas veces confesada: también se esconde un afán por comunicarse con el lector mediante un libro que sea válido en cualquier época y lugar. Borges, al contrario de lo que suele afirmarse, puede ser difícil, pero pocas veces pretende ser elitista. Buena prueba de ello es que, al construir su literatura, aspira a los valores clásicos, es decir, perdurables y universales. Cuando escribe "El inmortal», elige a Homero como símbolo de la literatura y del hombre; cuando reflexiona sobre la memoria, se decanta por Shakespeare («La memoria de Shakespeare»). Ambos autores, como Dante, son un símbolo más allá de sus obras. Han pasado por el toque de fuego de los siglos y, por ello, en la literatura de Borges son una moneda válida para comerciar con el lector.

Soy consciente de que las tres funciones que acabo de exponer no son compartimentos estancos. El texto y la figura de Dante son siempre algo más que un filón, un estímulo o un símbolo. Son, como diría Borges hablando de Virgilio, Dante y Beatriz, las tres cosas a la vez. Cuando Borges acude a la cantera de Dante en su memoria, las citas de la Comedia son también un símbolo, que a su vez funciona como estímulo en su poderosa imaginación. Una y otra vez, vuelven los mismos versos a la mente de Borges. Esos versos son algo más que un mero ejemplo para acompañar sus argumentos. Esos versos, a fuerza de ser usados, funcionan en manos de Borges como símbolo de cada una de las caras de que está compuesto el prisma de la literatura. Así, por citar solo un ejemplo, la trinidad formada por Beatriz, Dante y Virgilio se convierte en la moneda que explica la ambigüedad de la literatura, sus símbolos y sus alegorías (n. $10,12,29$ y 31 ).

\section{Borges descubre a Dante}

Nos han llegado cuatro testimonios sobre el primer encuentro de Borges y Dante. Los cuatro salieron de la pluma del propio escritor argentino. Es habitual que la crítica reproduzca el testimonio de A Literary Biography, de 1970 
(n. 14), pero rara vez se ha detenido a conjugar los cuatro testimonios y a observar las varias contradicciones que hay entre ellos. En el primero, fechado en 1958 (n. 13), Borges afirma que leyó por primera vez a Dante en «mil novecientos treinta y tantos» $(\$ 2)$, y que llegó a la Comedia a través de Chaucer y de la traducción de Longfellow, de la que leyó las notas, pero no el texto $(\$ 2)$. Antes de ese descubrimiento, el argentino se consideró muchos años enemistado con la edad media, en buena medida por culpa de la arquitectura gótica y las obras de Sir Walter Scott. De algún modo, gracias a Dante, Borges redescubrió la cultura medieval $(\$ 5)$. Poco tiempo después, cuando empezó a trabajar en la biblioteca Miguel Cané, compró la edición bilingüe de John Aitken Carlyle, y gracias a ella leyó la obra por primera vez $(\$ 5)$. Según sus biógrafos, Borges trabajó en la Miguel Cané entre 1937 y 1946². El que acabo de resumir es, a mi entender, el documento más fiable de cuantos disponemos, no solo porque en él la memoria de Borges conserva fresco aquel recuerdo, sino también porque los siguientes textos, de 1970 a 1979, incurren en contradicciones que se explican bien porque Borges quiso disfrazar poéticamente sus recuerdos, bien porque la memoria de hechos cada vez más lejanos le tendió varias trampas.

En 1970 (n. 14), Borges volvió sobre el asunto y añadió que su primer encuentro con Dante se produjo durante los largos viajes en tranvía que debía realizar a diario para llegar a la Miguel Cané. Había comprado la versión de Carlyle, publicada por la editorial Dent, en la librería Mitchell. Durante su lectura, se dejó guiar por el traductor hasta el Purgatorio (IV, \$ 8), y en 1977 (n. 10) precisa que abandonó la traducción inglesa al inicio del Paraíso, justo cuando Virgilio abandona a Dante. Es posible, como sugiere Terracini, que Borges haya reelaborado poéticamente este detalle para que coincidieran lector y personaje $\mathrm{e}^{3}$. En cualquier caso, son dos los aspectos que conviene aclarar respecto a estas confesiones. Es evidente que Borges, de 1958 a 1977, citó siempre la versión de Carlyle de memoria, porque en realidad Carlyle solo tradujo el Inferno. En la edición de Dent, que constaba de tres tomitos, tal como atestigua Borges, la traducción del Purgatorio estuvo al cargo de Thomas Okey, mientras que P. H. Wicksteed se ocupó del Paradiso ${ }^{4}$. No es raro que a Borges le falle la memoria en detalles concretos. Es lo que sucede en el segundo aspecto que conviene examinar. Hemos visto que Borges, tanto en 1958 como en 1970, sitúa la lectura de la Comedia en los años en los que trabajó en la Miguel Cané, y concretamente en los años treinta, es decir, entre 1937 y 1939.

2. María Esther VÁZQUEZ, Borges. Esplendor y derrota, Barcelona: Tusquets, 1996 (reed.: 1999), p. 156.

3. Lore Terracini, «Un lettore d'eccezione: Borges legge Dante», en su I codici del silenzio, Turín: Edizioni dell'Orso, 1988, p. 56.

4. El tomo del Inferno en la traducción de Carlyle fue impreso por vez primera en Londres por Chapman \& Hall, en 1849. La cuarta edición, publicada también en Londres, apareció en 1904 bajo el sello de George Bell \& Sons. Por su parte, Dent \& Co. lo reimprimió junto a los volúmenes de Okey y Wicksteed en Londres, 1901. Borges pudo haber utilizado la edición que Dent \& Sons publicó en Londres y Toronto en 1933. 
En una conferencia de 1977, no obstante, confiesa que la leyó «poco antes de la dictadura» (n. 10). Sin duda, Borges pensaba en la dictadura de José Félix Uriburu, que se alzó con el poder en 1930. Es poco probable, por otro lado, que la «dictadura» a la que remite sea el gobierno de Perón, que subió al poder en 1946. Este recuerdo, a cuarenta años de distancia, debe ser un lapsus, porque se contradice tanto con los testimonios recién mencionados, como con los textos de principios de los cuarenta en los que Borges demuestra haber asimilado el poema.

Sucede que, tras este primer encuentro, hay que esperar hasta 1943 para encontrar la primera referencia precisa que refleje la lectura de Dante. Es cierto que, como recuerda Terracini, la Comedia aparece mencionada en una fecha tan temprana como 1929 (n. 17) $)^{5}$, y en realidad podríamos retroceder hasta 1926 para hallar su primera aparición (n. 16). No obstante, las referencias a Dante en textos de los años 20 y 30 son tan generales que no presuponen la lectura del poema. Incluso en los casos en que Borges remite a pasajes concretos (n. 17, 69, 70 y 94), convendría aclarar si esas citas no proceden en realidad de Croce o Claudel, e incluso si fueron añadidas en reediciones posteriores ${ }^{6}$.

\section{El fervor}

Tras este primer descubrimiento, que habría de fascinar a Borges para toda la vida, se inicia una segunda etapa de profundización. Será, sin duda, el periodo más prolífico de su dantismo, y también el más provechoso de todos. Quizás el primer testimonio de una lectura en profundidad de algunos pasajes de la Comedia y sus comentaristas sea el «Poema conjetural», de 1943 (n. 87). El año clave, sin embargo, es el de 1946, cuando Perón ascendió al poder y Borges fue apartado de la biblioteca Miguel Cané. A raíz de esta decisión, gracias a la ayuda de sus amigos, se vio obligado a dar conferencias para subsistir. El peronismo, por tanto, convirtió a Borges en un conferenciante profesional, y su nuevo oficio lo obligó a organizar sus impresiones de lector, a poner en claro sus apuntes y a releer a sus autores predilectos para poder explicarlos con orden y coherencia. Sabemos que uno de los autores elegidos para sus conferencias fue Dante (n. 14, $\$ 13$ ). Los años del peronismo forzaron al escritor a encerrarse en la Comedia y trabajar en profundidad sobre algunos de sus pasajes. A su vez, esas conferencias le sirvieron como punto de partida para escribir la mayor parte de sus ensayos sobre el Alighieri, que se publicaron entre 1948 y 1951. En ese viaje hacia la obra de Dante, era inevitable que tropezara con sus comentaristas. En efecto, solo a partir de 1948 Borges empieza a prestar aten-

5. TERRACINI, op. cit., p. 56.

6. Resolver este enigma sería interesante en lo que concierne al n. 94, de 1931, pues en el caso de que el ejemplo de la Trinidad no se hallara en ninguno de los manuales que consultó Borges, y si además el pasaje en cuestión constara en la versión de 1931, este documento daría fe de una lectura del Paradiso anterior a ese año. Sin embargo, parece poco probable que Borges hubiera accedido al último libro de la Comedia en una fecha tan temprana. 
ción en sus ensayos a los editores y exegetas del Alighieri. De los veintiocho comentarios que alcanzó a citar, los de Momigliano, Grabher y Steiner fueron casi los únicos a los que se mantuvo fiel toda la vida.

Creo que 1955, el año en que Perón perdió el poder, debe considerarse el punto y final de toda una etapa en lo que atañe a Dante: a partir de entonces, la progresión de su ceguera lo obligó a depender de secretarios, alumnos y amigos para acceder a cualquier texto. Con pocas excepciones, a partir de entonces las referencias a Dante reciclarán los contenidos de sus artículos del periodo anterior, hasta el punto de que los tres únicos ensayos que dedicó a Dante después de 1955 delatan un manejo bibliográfico más limitado y tienden a ser visiones de conjunto sobre el poema italiano. De algún modo, la ceguera le obligó a recuperar y rehacer los artículos anteriores, y lo forzó a emplear su arsenal mnemotécnico de citas maestras, en las que condensó su poética de lectura de la Comedia.

Como ya habrá advertido el lector, los años más intensos de la lectura de Dante coinciden con la redacción de los cuentos de El Aleph (1949). Por ello no es extraño que buena parte de la crítica se haya esforzado en rastrear el modelo de la Comedia tras muchas de estas narraciones. De ellas, la que a primera vista ofrece más paralelos con el poema de Dante es «El Aleph», cuya imagen central, según Thiem, procede de Par. XXVIII-XXIX ${ }^{7}$. Las semejanzas entre el cuento y el poema, desveladas por Rodríguez Monegal, se limitan a la visión microcósmica del universo y a los nombres y el rol de Daneri y Beatriz. Estos aspectos ya han sido estudiados en profundidad y no conviene repetir aquí los argumentos de la crítica ${ }^{8}$. En otro orden de cosas, debemos a Paoli el estudio más penetrante acerca de la influencia de Dante en Borges ${ }^{9}$. Entre sus varias interpretaciones, destaca en especial la que vincula al Ulises dantesco, según la lectura de Borges, con los personajes Lönnrot y Dahlman, de los cuentos "La muerte y la brújula» y «El sur», respectivamente. Según Paoli, los tres personajes son víctimas de su propia temeridad, y en los tres casos el sur es símbolo de su perdición ${ }^{10}$. Paoli, además, observa que la biografía de los personajes se concentra en el instante previo a su muerte, generalmente violenta,

7. Jon Thiem, «Borges, Dante, and the Poetics of Total Vision», en Comparative Literature, 40 (1988), p. 101.

8. Cfr. Stelio Cro, Jorge Luis Borges, poeta, saggista, narratore, Milán: Mursia, 1971; Maria BONATTI, "Dante en la lectura de Borges», Revista iberoamericana, 100-101 (40 inquisiciones sobre Borges. Número especial dedicado a Jorge Luis Borges), 1977, p. 737-738; A. J. Carlos, "Dante y "El Aleph" de Borges», Duquesne Hispanic Review, V (1966), p. 3550; Georg-Rudolf Lind, "Die Dante-Parodie en J. L. Borges' Erzählung "El Aleph”", Literatur und Spiritualität: Hans Sckommodau zum siebzigsten Geburstag, edd. H. Rheinfelder y otros, Munich: Fink, 1978; Ruggiero STEFANINI, "Dante in Borges: l'Aleph, Beatriz e il Sud", en Italica, 57,1 (1980), p. 53-65; Roberto PAOLI, Borges percorsi di significato, Messina-Firenze: Casa Editrice d'Anna, 1977; Thiem, op. cit., y Rafael MonTANO, "El Aleph”: Dante y los dos Borges», en Revista Canadiense de Estudios Hispánicos, 27,2 (2003), p. 307-325.

9. PAOLI, op. cit.

10. Sobre este aspecto, cfr. también BONATTI, op. cit., p. 740. 
y que este rasgo era uno de los que el propio Borges había elogiado en la Comedia 11 .

La presencia de Dante en la poesía de Borges apenas ha sido abordada, aunque el excelente estudio de Carilla contiene en síntesis las claves para entender la asimilación de la Comedia en la poesía del escritor argentino ${ }^{12}$.

Además de asimilar a Dante en sus propias ficciones, Borges dedicó a la Comedia varios estudios que, como hemos indicado, parten del periodo que va de 1946 a 1955. Como todos los ensayos del escritor argentino, los que nos ocupan no son estrictamente académicos. Son, más bien, una prolongación de la propia poética de Borges. Sus exégesis pueden ser definidas, conforme a la afortunada fórmula de Terracini, como "filología fantástica» ${ }^{13}$. Borges entiende la crítica como la revelación de un secreto con implicaciones metafísicas ${ }^{14}$. En la crítica borgesiana, además, los textos de los otros se supeditan a los postulados de la propia poética del crítico $^{15}$. No es extraño, por ello, que el autor argentino se fije en los pormenores de la Comedia y en la facilidad con la que Dante encierra en pocos versos toda una vida o un carácter complejo. En este sentido, Borges ve en Dante a un miniaturista y a un orfebre minucioso ${ }^{16}$. Fruto de esta óptica deformada, Dante se convierte, en sus estudios, en una invención del crítico e, incluso, como propone Almeida, en un escritor borgesiano $^{17}$. El procedimiento para hacerlo posible es el mismo que emplea en la mayor parte de sus ensayos y conferencias: Borges se sirve de un punto de vista omnisciente que le permite adoptar la visión de Dante en el momento preciso de componer los versos de su Comedia ${ }^{18}$. Este mirador privilegiado propicia que su exégesis equivalga a la revelación de un secreto que se había mantenido oculto durante siglos y que ahora puede compartir con sus lectores. De este modo se explica la omnipresencia del crítico dentro de sus ensayos, hasta el

11. Cfr., asimismo, Ivan AlmeIDA, «Borges, Dante et la modification du passé», en Variaciones Borges, 4 (1997), p. 78, y Laura SILVESTRI, («Borges y Dante o la superstición de la literatura», en El siglo de Borges, I, Retrospectiva. Presente. Futuro, ed. Alfonso DE TORO y Fernando DE TORO, Madrid: Vervuert-Iberoamericana, 1999, p. 399. Almeida, op. cit., p. 84-94, por su parte, sostiene que Dante también está presente en el relato "La otra muerte».

12. Emilio Carilla, "Un poema de Borges. El "Poema conjetural”", Estudios de literatura hispanoamericana, Bogotá: Instituto Caro y Cuervo, 1977, p. 313-334. Cfr., además, Silvia MAGNAVACCA, "Un tema dantesco en la poesía de Borges», en Borges y la filosofía, comp. Gregorio Kaminsky, Universidad de Buenos Aires, 1994, p. 161-169.

13. TERRACINI, op. cit., p. 64.

14. Almeida, op. cit., p. 79.

15. Según SiLVESTRI, op. cit., p. 385-386, «todas sus reflexiones sobre el antiguo poeta, podrían ser leídas como el manifiesto de su poética. [...] Lo que Borges ensalza en la Divina Comedia, en efecto, constituye también la característica de su propia obra».

16. "Cada detalle vale para Borges por todo el poema, pero no porque lo represente, porque dé una versión microcósmica de su grandiosidad, sino porque en su lectura se pueden experimentar todas las potencias de conmoción y de goce de que el poema es capaz» (Alberto GIORDANO, "Borges y la ética del lector inocente (Sobre los Nueve ensayos dantescos)», en Variaciones Borges, 4 (1997), p. 65). Cfr. también AlmEIDA, op. cit., p. 77.

17. Almeida, op. cit., p. 77 y 80.

18. Giordano, op. cit., p. 72; Almeida, op. cit., p. 75-80; Terracini, op. cit., p. 65. 
punto de que acaba por convertirse en un personaje más dentro de una investigación con tintes detectivescos ${ }^{19}$. Por todos estos motivos, Almeida sostiene que la Comedia, en manos del argentino, es una invención de Borges, aunque Terracini prefiere hablar de actualización ${ }^{20}$.

\section{Las obsesiones}

He señalado hace un momento que la poderosa memoria de Borges es selectiva. Ciertos pasajes de la Comedia se grabaron en su mente con especial intensidad, y a ellos vuelve una y otra vez. Durante su ceguera, y en especial cuando se vio obligado a impartir conferencias a partir de los años sesenta, utilizó las mismas citas que poblaban los ensayos del periodo de 1948-1955, y a menudo repitió las observaciones que ya aparecían allí. De algún modo, todo el Borges dantista se encuentra en los ensayos de esa época.

Da la sensación de que algunas parcelas de la Divina Comedia solo obsesionaron a Borges durante unos pocos años, y que después cayeron en el olvido. Es lo que sucede, por ejemplo, con la alegoría de la loba de Inf. I (n. 69-70), que aparece en dos textos de 1937 (idénticos, por cierto) para desaparecer luego de forma definitiva. También es el caso de Inf. IV 39, citado en sendos pasajes de 1949 y 1951; Inf. IV 86, que solo aparece en dos textos de 1957; Inf. V 129, presente en un ensayo de 1977 y que inspiró un poema publicado en 1981; Inf. XXXIII 75, que Borges solo cita en 1948 y 1958; el pasaje del Purgatorio donde aparece Buonconte da Montefeltro, que dio lugar al hermoso poema de 1943 y que solo vuelve a asomar en un trabajo de 1951, y, finalmente, Purg. XI 100102, mencionado en 1948 y 1951 para desaparecer en los ensayos posteriores.

Por contra, otros estímulos perdurarán gracias a los textos de 1948-1951. Borges, en sus conferencias y trabajos posteriores a los sesenta, volvió a esos ensayos con el propósito de transformarlos en material para sus charlas. Hay ejemplos muy elocuentes de este proceso. El caso de Virgilio, Dante y Beatriz, que en dos trabajos de 1949 le había servido para exponer sus ideas sobre la alegoría, reaparece en textos de 1977 y 1982; otro tanto sucede con los juegos numéricos de la Comedia, explorados en varios ensayos de 1951-1958 y que aparecen reciclados en otros de 1975 y 1978, y lo mismo puede decirse de $\operatorname{Inf}$. I 60, citado en un ensayo de 1951 y en otro de 1982.

Borges jugó a creer que Dante, justo antes de morir o en el disperso instante del sueño, alcanzó a recibir la revelación de la verdad (n. 71), que es la rosa amarilla de la víspera de Marino (n. 40). La lectura, audaz y penetrante, que Borges dedica a la Divina Comedia se asienta sobre la sospecha de que tras el poema pueden ocultarse las claves del universo. Esa creencia justifica el fervor con el que Borges conservó muchos de sus mejores versos en su memoria.

19. Terracini, op. cit., p. 61, se había referido a la enérgica presencia personal de Borges en sus ensayos; SILVESTRI, op. cit., p. 387-391, por su parte, la relaciona con la aparición de Dante en la Comedia.

20. Almeida, op. cit., p. 84, y Terracini, op. cit., p. 53-54. 


\section{El corpus}

El objetivo central de este artículo es ofrecer un corpus de las apariciones de Dante en la obra de Borges. Sin duda, el corpus será incompleto, bien sea por las negligencias involuntarias de quien esto firma, bien porque aún no disponemos de una edición crítica e íntegra de los textos borgesianos. De todas formas, el corpus pretende ser un primer instrumento útil para el estudio del dantismo de Borges, que es sin duda uno de los más creativos y fascinantes del siglo XX. He creído que lo más práctico era dividir los documentos en cinco apartados: en el primero aparecen los estudios que Borges dedicó en exclusiva a la Comedia; en el segundo se mencionan aquellos textos autobiográficos en los que Borges habló de su relación personal con la Comedia; en el tercero, ordenadas cronológicamente, aparecen las menciones generales que no remiten a ningún pasaje determinado del poema italiano; el cuarto apartado ordena los pasajes de la Comedia que Borges examinó o tuvo en cuenta a lo largo de su obra, y, finalmente, añado un índice de los comentaristas a los que el argentino aludió en sus ensayos. Es tal la cantidad de referencias al poema italiano rastreables en las obras del argentino, que era del todo imprescindible disponer de un elenco ordenado de todas ellas. Confío en que el discreto lector considere cubierto este humilde objetivo ${ }^{21}$.

\section{Estudios dedicados a la Divina Comedia}

0. 1949. «Prólogo» a la edición de la Divina Comedia de 1949; reed. con modificaciones en Nueve ensayos dantescos (1982). Aparecen alusiones a Inf. III 124, IV 39, XV 9, XXV 64, XXXII 24, Purg. III 34, VI 58, Par IV 49 y Conv. III 5. Comentaristas mencionados: Claudel, Iacopo di Dante, Iacopo della Lana y Francesco da Buti.

1. III-1948. «El enigma de Ulises», Escritura, Montevideo; Textos recobrados 1931-1955 (2001). Comentario de Inf. XXVI 90-142.

2. 14-III-1948. "El simurgh y el águila», La Nación, Buenos Aires (14-III1948); Nueve ensayos dantescos (1982). Aparecen alusiones a Par. XVIII y XIX 11. Comentaristas mencionados: Tommaso Casini y Guido Vitali.

3. V-1948. «El verdugo piadoso», Sur, mayo de 1948; Nueve ensayos dantes$\cos (1982)$.

21. Además de los trabajos citados en notas anteriores, otros investigadores se han ocupado, desde distintas perspectivas, de la presencia de Dante en la obra de Borges. Cfr. Joaquín ARCE, presentación de Nueve ensayos dantescos, Madrid: Espasa Calpe, 1982 (reed.: 1999), p. 75-80; Marcos Ricardo BARNATÁN, introducción a Nueve ensayos dantescos, Madrid: Espasa Calpe, 1982 (reed.: 1999), p. 9-73; José M. CUESTA ABAD, Ficciones de una crisis. Poética e interpretación en Borges, Madrid: Gredos (Biblioteca Románica Hispánica, II, 392), 1995; Biagio D’Angelo, «Dante, Borges e il libro», Memorandum, 3 (2002), p. 5-13; Roxana KREIMER, «Dante y Borges: nacimiento y crítica del sujeto moderno», 2004, en http://www.geocities.com/filosofialiteratura/BorgesDanteYo.htm; David SoRNIG, «Borges, Dante and the Golem: In Search of the fallible God in Spiel», en Text, 7,1 (2003). 
4. 30-V-1948. «El falso problema de Ugolino», La Nación, Buenos Aires (30V-1948); Nueve ensayos dantescos (1982). Examina con detalle el Inf. XXXIII 75. Comentaristas mencionados: Rambaldi da Imola, Francesco Torraca, Guido Vitali, Tommaso Casini, Benedetto Croce, Bianchi, Luigi Pietrobono, Francesco De Sanctis y Francesco D'Ovidio.

5. 22-VIII-1948. "El último viaje de Ulises», La Nación, Buenos Aires (22VIII-1948); Nueve ensayos dantescos (1982). Comentario de Inf. XXVI 90142 y nueva versión de «El enigma de Ulises» (n. 1). Aparecen alusiones a Purg. XI 100-102 y Par. XXVII 82-83. Comentaristas mencionados: Anónimo Florentino, Raffaele Ancheoli, Tommaseo, Casini, Pietrobono, Hugo Friedrich, Carlo Steiner y August Ruegg.

6. 3-X-1948. "El encuentro en un sueño", La Nación, Buenos Aires (3-X1948); Nueve ensayos dantescos (1982). Comentario de Purg. XXIX. Aparece una alusión a Purg. XXXI 121. Comentaristas mencionados: Tommaseo, Lombardi, Pietro di Dante, Francesco da Buti, Benvenuto da Imola, Luigi Pietrobono, Dridon, Vitali, Steiner y Torraca.

7. 22-IV-1951. «El noble castillo del canto IV», La Nación, Buenos Aires (22-IV1951); Nueve ensayos dantescos (1982). Borges, en $\$ 1$, cita la referencia al Inf. que incluyó en su estudio «Sobre el Vathek de William Bedford» (n. 25). Aparecen alusiones a Inf. IV 101, 123, y Purg. XI 100-102. Comentaristas citados: Guido Vitali, Momigliano, Francesco Torraca y Benedetto Croce.

8. 1957. "Dante y los visionarios anglosajones", Ars, 1957; Nueve ensayos dantescos (1982). Comentario de Par. X. Aparecen alusiones a Inf. II 93, IV 86 y Purg. XXX 51.

9. 1961. «Italia», Lyra, Buenos Aires; Textos recobrados 1956-1986 (2003). Texto dedicado exclusivamente a Dante; destacan las afirmaciones: «Pensar en Italia es pensar en Dante» $(\$ 1)$, «[Dante es] tal vez el primer poeta del mundo» $(\$ 1)$, y «Dante [es] el poeta arquetípico de Italia y, por ende, de todo Occidente» $(\$ 1)$.

10. 1-VI-1977. "La Divina Comedia», conferencia fechada; La Opinión, Buenos Aires (10-VIII-1977); Siete noches (1980). Aparecen alusiones a Inf. I 1-2, IV 106-151, V, V 142, XVII 127-136, XXVI, Purg. I 13, Par. XVII 23-24. Comentaristas mencionados: Claudel, Momigliano, Grabher, John A. Carlyle.

11. 1982. "Purgatorio, I, 13", Nueve ensayos dantescos (1982). Aparece una mención a Inf. I 60.

12. 1982. "La última sonrisa de Beatriz», Nueve ensayos dantescos (1982). Comentario de Par. XXXI. Aparece una alusión a Par. XXX 118. Comentaristas mencionados: Torraca, Pietrobono, Casini, Vitali y De Sanctis.

Recuerdos autobiográficos sobre su conocimiento de Dante (véase n. 10, $\$ 10-14$, de junio de 1977)

13. 1958. "Mi primer encuentro con Dante (Resumen de una conferencia)» fechado; Quaderni Italiani di Buenos Aires, Buenos Aires, 7-IV-1961; Textos recobrados 1956-1986 (2003). 
14. 1970. "A Literary Biography» (IV, \$ 8), New Yorker, 19-IX-1970, a partir de una conferencia de 1970; Un ensayo autobiográfico (1999).

15. 26-VIII-1979. "El taller del escritor» (encuesta; $\$$ 8), La Prensa, Buenos Aires; Textos recobrados 1956-1986 (2003). Respuesta a la pregunta Qué estoy escribiendo: "Una recopilación de los textos que escribí, durante la dictadura, sobre la Divina Comedia. No sé italiano; lo poco y lo memorable que sé me fue enseñado por Dante, por Ariosto y por Croce. Habré leído la Comedia nueve o diez veces, en ediciones distintas. Los comentadores son admirables; Momigliano y Grabher anotan cada verso de la obra. Mediante ese ordenado y lúcido auxilio, un lector de lengua española puede enfrentarse con el texto, de manera inmediata».

\section{Dante como estímulo general}

16. 1926. "Las coplas acriolladas» (\$ 6), Nosotros, Buenos Aires, enero-febrero de 1926; El tamaño de mi esperanza (1926). A propósito de unos versos criollos, Borges escribe: "Confesión de Juicio Final, resumen de un vivir, alegato para lo eterno son los versos de veras y no pensaron en otra cosa el salmista y Jorge Manrique y el Dante y Browning y Unamuno y Whitman y quizá nuestro payador».

17. 1929. "La duración del Infierno», Sintesis, Buenos Aires, mayo de 1929; Discusión (1932). Borges menciona la alegría de Tertuliano cuando se imagina a los pecadores el día del Juicio Final, y añade: «El mismo Dante, en su gran tarea de prever en modo anecdótico algunas decisiones de la divina Justicia relacionadas con el Norte de Italia, ignora un entusiasmo igual» $(\$ 1)$. Véase n. 10, $\$ 50$ (de junio de 1977).

18. 1932. "La poesía gauchesca» (\$ 41), Discusión (1932). Agrupa las distintas actitudes de la crítica frente al Martin Fierro: «La segunda - la del hiperbólico elogio — no ha realizado hasta hoy sino el sacrificio inútil de sus "precursores» y una forzada igualación con el Cantar del Cid y con la Comedia dantesca».

19. 2-VI-1935. "Las pesadillas y Franz Kafka» (\$ 1), La Prensa, Buenos Aires; Textos recobrados 1931-1955 (2001). "En cuanto a los "soñadores" proféticos - Isaías, Ezequiel, San Juan el Teólogo, Dante, John Bunyan-, su estilo continuado y autoritario en nada se parece al de nuestros sueños.»

20. 5-II-1937. «James Joyce», El Hogar; reed.: Textos cautivos. «Siempre lo atrajeron las obras vastas, las que abarcan un mundo: Dante, Shakespeare, Homero, Tomás de Aquino, Aristóteles, el Zohar» (\$ 1).

21. 24-II-1939. "Dante’s Purgatorio, de Laurence Binyon", El Hogar (24-II1939). Obra no vista.

22. 21-IV-1939. "Introducing Shakespeare, de G. B. Harrison», El Hogar; reed.: Textos cautivos. "El goetheano, el dantista, el shakespeariano habitan un orbe complejo; el cervantista es un coleccionador de proverbios» $(\$ 2)$.

23. 1941. «Sobre los clásicos» (\$ 4), Sur, octubre de 1941; Otras inquisiciones (1952). "Libros como el de Job, la Divina Comedia, Macbeth (y, para mí, 
algunas de las sagas del Norte) prometen una larga inmortalidad, pero nada sabemos del porvenir, salvo que diferirá del presente.»

24. 4-VIII-1942. "Las previsiones de Sangiácomo» (II, $\$ 10$ ), fechado; Seis problemas para don Isidro Parodi (1942). Un personaje aconseja a otro que guarde lo que escribe durante nueve años; el otro responde: «¿Nueve años? ¡Hace quinientos años que el Dante publicó la Divina Comedia!».

25. 1943. "Sobre el Vathek de William Beckford» (\$ 5 y 6), fechado; La Nación, Buenos Aires (4-IV-1943); Otras inquisiciones (1952). «Arriesgo esta paradoja: el más ilustre de los avernos literarios, el dolente regno de la Comedia, no es un lugar atroz; es un lugar en el que ocurren hechos atroces.» $(\$ 5)$ «La Divina Comedia es el libro más justificable y más firme de todas las literaturas: Vathek es una mera curiosidad.» (\$ 6), citado en el n. 7 de abril de 1951. Véanse n. 55 (de 1976), 76 (de 1980) y 62 (de 1984).

26. 1944. "Tres versiones de Judas» (\$ 1), fechado en 1944; Sur, agosto de 1944; Ficciones (1944). Hablando del hereje Nils Runeberg: «Dante le hubiera destinado, tal vez, un sepulcro de fuego".

27. 1945. "Moral y literatura» (encuesta; $\$ 4$ ), Sur, abril de 1945; Borges en Sur (1999). "Vedar la ética es arbitrariamente empobrecer la literatura. La puritánica doctrina del arte por el arte nos privaría de los trágicos griegos, de Lucrecio, de Virgilio, de Juvenal, de las Escrituras, de San Agustín, de Dante, de Montaigne, de Shakespeare, de Quevedo, de Browne, de Swift, de Voltaire, de Johnson, de Blake, de Hugo, de Emerson, de Whitman, de Baudelaire, de Ibsen, de Butler, de Nietzsche, de Chesterton, de Shaw; casi del universo.»

28. 1948. "Quevedo» (\$ 2), prólogo a F. de Quevedo, Prosa y verso (1948); Otras inquisiciones (1952). Para explicar por qué Quevedo ha padecido una "gloria parcial» en la literatura, contrapone aquellos escritores que han forjado un símbolo duradero (Homero, Sófocles, Lucrecio, Dante, Shakespeare, Cervantes, Swift, Melville y Kafka) a la "grandeza» exclusivamente «verbal» $(\$ 4)$ del poeta conceptista. El símbolo que identifica a Dante son «los nueve círculos infernales y la Rosa paradisíaca». El ensayo acaba con estas palabras: "Como Joyce, como Goethe, como Shakespeare, como Dante, como ningún otro escritor, Francisco de Quevedo es menos un hombre que una dilatada y compleja literatura» $(\$ 14)$.

29. 1949. "De las alegorías a las novelas» (\$ 3), La Nación, Buenos Aires, 7VIII-1949; Otras inquisiciones (1952). Rechaza la interpretación de Croce, según el cual las alegorías son «laboriosos enigmas» que encierran un sentido «inmediato o literal (Dante, guiado por Virgilio, llega a Beatriz), y [otro] figurativo (el hombre finalmente llega a la fe, guiado por la razón)». Dante, en su Vita nuova, defendió la alegoría, que el lector actual considera «intolerable» $(\$ 5)$. Dante, como todos los medievales, invoca a Aristóteles, "maestro de la humana razón (Convivio, IV, 2)» (\$6). Véanse los n. $10, \$ 5$ (de junio de 1977), 12, $\$ 1$ (de 1982) y 31 (de 1949).

30. 1949. "Historia del guerrero y de la cautiva» (\$ 4), Sur, mayo de 1949; El Aleph (1949). Inspirado por un pasaje de La poesía, de Croce, Borges refie- 
re la vida del bárbaro Droctfuld, seducido por la civilización: «Al cabo de unas cuantas generaciones, los longobardos que culparon al tránsfuga procedieron como él; se hicieron italianos, lombardos y acaso alguno de su sangre - Aldíger - pudo engendrar a quienes engendraron al Alighieri...".

31. 1949. "Nathaniel Hawthorne» ( $\$ 5$ y 6), Cursos y conferencias, Buenos Aires, julio de 1949; Otras inquisiciones (1952). Rechaza la interpretación que hace Croce de la alegoría, que a su entender es un simple esquema. Según Borges, «Beatriz no es un emblema de la fe, un trabajoso y arbitrario sinónimo de la palabra $f e$; la verdad es que en el mundo hay una cosa - un sentimiento peculiar, un proceso íntimo, una serie de estados análogos - que cabe indicar por dos símbolos: uno, asaz pobre, el sonido fe; otro, Beatriz, la gloriosa Beatriz que bajó del cielo y dejó sus huellas en el Infierno para salvar a Dante» (\$ 6). Según Croce, en cambio, «Dante es el alma, Virgilio la filosofía o la razón o la luz natural, y Beatriz la teología o la gracia» (\$5). Véanse los n. 10, $\$ 5$ (de junio de 1977), 12, $\$ 1$ (de 1982) y 29 (de 1949).

32. 1951. "Literatura de la Inglaterra sajona» (Cynewulf, \$ 2), Antiguas literaturas germánicas (1951, junto a Delia Ingenieros); Literaturas germánicas medievales (1966, junto a María Esther Vázquez). «Muchos son los poetas (Virgilio, Dante, Ronsard, Cervantes, Whitman, Browning, Lugones, los persas) que han intercalado sus nombres en sus composiciones.»

33. 1951. "Literatura escandinava» (Las sagas, \$ 6), Antiguas literaturas germánicas (1951, junto a Delia Ingenieros); Literaturas germánicas medievales (1966, junto a María Esther Vázquez). «en la misma Vita nuova de Dante, que refiere de modo autobiográfico la historia de su pasión por Beatriz, hay complicados juegos numéricos y uno de los editores advierte que la obra no puede ser interpretada literalmente, añade que Dante no ha querido historiar hechos inmediatos.» Véanse n. 37 (de 1951), 13, $\$ 3$ y 4 (de 1958), 53 (de 1975) y 59 (de junio de 1978).

34. 1951. «La esfera de Pascal» (\$ 4), La Nación, Buenos Aires, 14-I-1951; Otras inquisiciones (1952). Dante conserva la visión ptolemaica del cosmos. Véase n. 13, $\$ 3$ (de 1958).

35. 1953. «El gaucho Martín Fierro» (\$ 3), El «Martín Fierro» (1953). Lugones remitió a la tradición épica la invocación a la divinidad que aparece en la segunda copla del Martín Fierro; Borges añade que «tales invocaciones (que también figuran en la poesía de las naciones orientales y cuyo empleo ha sido preconizado por Dante en una epístola famosa) no son herencia mecánica de la Ilíada; proceden de una convicción instintiva de que lo poético no es obra de la razón, sino el dictado de poderes ocultos».

36. 1953. «Martín Fierro y los críticos» (\$ 11), El «Martín Fierro» (1953). A propósito del concepto de libro canónico nacional: «Carlyle escribió que Italia se cifraba en la Divina Comedia y España en el Quijote y agregó que la casi infinita Rusia era muda, porque aún no se había manifestado en un libro.» Véase n. 50 (de 1970). 
37. 1953. «Destino escandinavo» (\$ 13), Sur, enero-febrero de 1953; Borges en Sur (1999). "El arte medieval es connaturalmente alegórico; así, en la Vita Nuova, que es un relato de orden autobiográfico, la cronología de los hechos está supeditada al número 9, y Dante conjetura que la misma Beatriz era un nueve, "es decir un milagro, cuya raíz es la Trinidad". Ello ocurrió hacia 1292.» Véase una explicación parecida en n. $0, \$ 4$ (de 1949) y 33 (de 1951).

38. 8-XII-1955. "Alfonso Reyes» (\$2), fechado; México en la Cultura, octubre-noviembre-diciembre de 1955; Textos recobrados 1931-1955 (2001). «Dos virtudes de México, el valor y la cortesía, están en su obra, esas virtudes cuya perdición en Florencia deploró Dante.»

39. 24-XI-1957. «Montaigne, Walt Whitman» (\$ 8), plaqueta de 1957; Textos recobrados 1956-1986 (2003). «Whitman quería que ese nuevo orden se proyectara en su libro, como el orden medieval se había proyectado en el libro de Dante.»

40. 1960. «La rosa amarilla» (\$ 1 y 3), El hacedor (1960). Giambattista Marino, «el nuevo Homero y el nuevo Dante» según la Fama, recibe antes de morir la revelación de lo indecible. «Esta iluminación alcanzó Marino en la víspera de su muerte, y Homero y Dante acaso la alcanzaron también.» Véanse n. 71 (de 1955), 56 (de 1977) y 72 (de 1986).

41. 1961. "Discurso" [Homenaje a don Luis de Góngora] (\$1), Boletín de la Academia Argentina de Letras, Buenos Aires, julio-diciembre de 1961; Textos recobrados 1956-1986 (2003). "Yo casi llegaría a decir que Góngora no es un poeta visual en el sentido en que Dante Alighieri lo es, o como lo es Wordsworth.» Véanse n. 13, $\$ 5$ (de 1958) y 10, $\$ 37$ (de junio de 1977).

42. 1965. «El movimiento romántico» (\$7), Introducción a la literatura inglesa (1965, junto a María Esther Vázquez). A propósito de Coleridge, Borges escribe: «Sus obras poéticas [...] pueden reducirse a tres poemas, de los que alguien ha dicho que forman una especie de Divina Comedia. El primero, Christabel, correspondería al infierno; el segundo, La balada del viejo marinero, al purgatorio. [...] El tercero, Kubla Khan, sería el paraíso».

43. 1965. "Lugones, poeta» (\$ 6), Leopoldo Lugones (1965, junto a Betina Edelberg). A propósito de Las montañas de oro (1897), de Lugones: «Dante y Homero, dos admiraciones que lo acompañarán hasta el fin de sus días, ya son celebrados en este libro».

44. 1966. "Homenaje a César Paladión» (\$ 5), Crónicas de Bustos Domecq (1967, junto a Adolfo Bioy Casares). "iModestia inmarcesible la de este hombre que, ante el banquete que le brindan las bibliotecas orientales y occidentales, renuncia a la Divina Comedia y a Las Mil y Una Noches y condesciende, humano y afable, a Thebussianas (segunda serie)!»

45. 1966. "Naturalismo al día» (\$ 3-6), Crónicas de Bustos Domecq (1967, junto a Adolfo Bioy Casares). Parodia del crítico ficticio Hilario Lambkin Formento, que para describir la Divina Comedia la reproduce palabra por palabra a partir de «la acreditada edición de Dino Provenzal», del mismo modo que un «Mapa del Imperio» descrito en un libro del siglo XVII «tenía el tamaño del Imperio» (\$ 4 ). Injustamente, los lectores toman el estudio 
por una edición más $(\$ 6)$. Este personaje ofrece paralelos con Carlos Argentino Daneri («El Aleph», 1945; El Aleph, 1949) y Pierre Menard («Pierre Menard, autor del Quijote», 1939; Ficciones, 1944).

46. 1967. "Trascendentalismo» (\$12), Introducción a la literatura norteamericana (1967, junto a Esther Zemborain de Torres Duggan). Referencia a la traducción de la Comedia que ejecutó Longfellow, «una de las mejores traducciones inglesas [...] enriquecida de curiosas notas». En el n. 13, $\$ 2$ (de 1958), Borges afirma que se introdujo a Dante por medio de los comentarios de Longfellow. Véanse también n. 60 (de 1978) y 92 (de 1978).

47. 24-X-1967. «El enigma de la poesía» (\$ 4), Arte poética (2001); original inglés de 2000. "Ahora bien, es fácil que incurramos en un error muy común. Pensamos, por ejemplo, que, si estudiamos a Homero, la Divina Comedia, Fray Luis de León o Macbeth, estudiamos la poesía. Pero los libros son sólo ocasiones para la poesía».

48. 6-XII-1967. «El arte de contar historias» (\$ 20), Arte poética (2001); original inglés de 2000. Compara a los protagonistas del Ulisses de Joyce con los de otros clásicos: "Conocemos mejor a los personajes de Dante o de Shakespeare, que se nos presentan — que viven y mueren- en unas pocas frases. No conocemos miles de circunstancias sobre ellos, pero los conocemos íntimamente. Eso, desde luego, es mucho más importante». Véase n. 10, $\$ 37$ (de junio de 1977).

49. 1969. "Prólogo» (\$ 1), fechado; Cuaderno San Martín (1929; reed. 1969). Borges se retracta de haber clasificado a los poetas en líricos e intelectuales, y se pregunta: «¿Cómo clasificar a Shakespeare o a Dante?».

50. 1970. «El matrero» (\$ 1), prólogo al libro homónimo de 1970; Prólogos con un prólogo de prólogos (1975). Cada gran país tiene «su libro clásico. Inglaterra ha elegido a Shakespeare, el menos inglés de los escritores ingleses; Alemania, tal vez para contrarrestar sus propios defectos, a Goethe, que tenía en poco a su admirable instrumento, el idioma alemán; Italia, irrefutablemente, al alígero Dante, para repetir el melancólico calembour de Baltasar Gracián; Portugal, a Camoens; España, apoteosis que hubiera suscitado el docto escándalo de Quevedo y de Lope, al ingenioso lego Cervantes; Noruega, a Ibsen; Suecia, creo, se ha resignado a Strindberg. En Francia, donde las tradiciones son tantas, Voltaire no es menos clásico que Ronsard, ni Hugo que la Chanson de Roland; Whitman, en los Estados Unidos, no desplaza a Melville ni a Emerson». Argentina ha elegido el Martín Fierro; Borges habría preferido el Facundo. Véase n. 36 (de 1953). Para el adjetivo «alígero», véase n. 54 (de 1976).

51. 20-XII-1970. «Los amigos» (\$ 11), fechado; Tiempo de sosiego, folleto de 1972; Textos recobrados 1956-1986 (2003). Diferencia entre hombres de talento y de genio: «La diferencia, creo, está en el hecho de que los últimos nos dan la impresión de un gran vuelo intenso y espléndido, no exento de alguna irresponsabilidad y de caídas bruscas. (Dante, que gobernaba sabiamente su obra, fue un talento y un genio; Shakespeare fue sólo un genio. Lo mismo diría yo de Walt Whitman y de nuestro Sarmiento)». 
52. VII-1974. «Norah» (\$ 7), fechado; Norah, con quindici litografie di Norah Borges (1977); Textos recobrados 1956-1986 (2003). Hablando de los gustos de su hermana, afirma: «Literariamente, nunca he logrado convertirla al Quijote, a Dante o a Conrad».

53. a. 1975. «Emanuel Swedenborg» (\$12), prólogo a la edición homónima sin fecha; Prólogos con un prólogo de prólogos (1975). «En una epístola famosa, dirigida a Can Grande della Scala, Dante Alighieri advierte que su Comedia, como la Sagrada Escritura, puede leerse de cuatro modos distintos y que el literal no es más que uno de ellos. Dominado por los versos precisos, el lector, sin embargo, conserva la indeleble impresión de que los nueve círculos del Infierno, las nueve terrazas del Purgatorio y los nueve Cielos del Paraíso corresponden a tres establecimientos: uno de carácter penal, otro penitencial, y otro - si el neologismo es tolerable- premial. Pasajes como Lasciate ogni speranza, voi ch'entrate fortalecen esa convicción topográfica, realzada por el arte.» Véanse n. 13, \$3 (de 1958) y 65 (de 1985). Para los cuatro sentidos de la Comedia, n. 33 (de 1951), 13, \$3 y 4 (de 1958) y 59 (de junio de 1978).

54. 1976. «Lewis Carrol, Obras completas» (\$ 6), Prólogos con un prólogo de prólogos (1975); prólogo a la edición de Carrol de 1976. «El retruécano es, por lo general, un mero alarde bobo de ingenio ("el alígero Dante", "el culto pero no oculto Góngora” de Baltasar Gracián).» Véase n. 50 (de 1970).

55. 27-X-1976. «Jorge Luis Borges: Libro de sueños» (\$ 7), fechado; Prólogos de La Biblioteca de Babel (1995). «El arte de la noche ha ido penetrando en el arte del día. La invasión ha durado siglos; el doliente reino de la Comedia no es una pesadilla, salvo quizá en el canto cuarto, de reprimido malestar: es un lugar en el que ocurren hechos atroces». Véanse n. 25 (de 1943), 7, \$1 (de abril de 1951), 76 (de 1980) y 62 (de 1984).

56. 1977. "Things that might have been", Historia de la noche (1977). Entre las "cosas que pudieron ser y no fueron", menciona «La obra inconcebible que a Dante le fue dado acaso entrever, / ya corregido el último verso de la Comedia». Véanse n. 71 (de 1955), 40 (de 1960) y 72 (de 1986).

57. 1977. «The Thing I Am», Historia de la noche (1977). «Soy su mirada, pero soy el otro / que estuvo, como Dante y como todos / los hombres, en el raro Paraíso / y en los muchos Infiernos necesarios.»

58. 1977. «Las causas», Historia de la noche (1977). Entre las muchas causas necesarias "para que nuestras manos se encontraran», se menciona "El ordenado Paraíso». Véase n. 64 (de 1985).

59. 9-VI-1978. «Emanuel Swedenborg» ( $\$ 11,33$ y 42), conferencia fechada; Borges oral (1979). «En la Divina Comedia de Dante —esa obra tan hermosa literariamente- el libre albedrío cesa en el momento de la muerte. Los muertos son condenados por un tribunal y merecen el cielo o el infierno." $(\$ 11)$ Swedenborg afirmaba «que cada palabra en la Biblia tiene por lo menos dos sentidos. Dante creía que había cuatro sentidos para cada pasaje» (\$33). «En el caso de Dante, que también nos ofrece una descripción 
del Infierno, del Purgatorio y del Paraíso, entendemos que se trata de una ficción literaria.» (\$ 42) Véanse n. 33 (de 1951), 13, \$3 y 4 (de 1958) y 53 (de 1975).

60. 19-X-1978. «La sepultura» (\$ 4); Clarín, Buenos Aires; Textos recobrados 1956-1986 (2003). Menciona la traducción de la Comedia ejecutada por Longfellow. Véanse n. 13, $\$ 2$ (1958), 46 (de 1967), y 92 (de 1978).

61. 25-II-1979. «V. O.» (\$ 2), La Nación, Buenos Aires; Textos recobrados 19561986 (2003). Evocación de Victoria Ocampo, quien «Fue una lectora hedónica; leía a Shakespeare o a Dante con la misma curiosidad con que leía a Valéry o a Virginia Woolf».

62. 1984. «William Beckford: Vathek» (\$ 3), Prólogos de La Biblioteca de Babel (1995). Borges compara el Infierno de Beckford con el dantesco: «el infierno dantesco magnifica la noción de una cárcel; el de Beckford, los túneles de una pesadilla. La Divina Comedia es el libro más justificable y más firme de todas las literaturas: Vathek es una mera curiosidad, the perfume and suppliance of a minute». Véanse n. 25 (de 1943), 7, \$ 1 (de abril de 1951), 55 (de 1976) y 76 (de 1980).

63. 1985. "Gilbert Keith Chesterton: El ojo de Apolo» (\$ 7), Prólogos de La Biblioteca de Babel (1995). Hablando de las creencias de Chesterton, Borges afirma: «No comparto su teología, como no comparto la que inspiró la Divina Comedia, pero sé que las dos fueron imprescindibles para la concepción de la obra».

64. 1985. "La trama», Los conjurados (1985). En las muchas causas del presente, se menciona «El rocío en la hierba del Paraíso». Véase n. 58 (de 1977).

65. 1985. "Evangelios apócrifos» (\$ 3), Biblioteca personal (1988). «Para el antiguo Testamento, el Infierno (Sheol) es la sepultura; para los tercetos de la Comedia, un sistema de cárceles subterráneas de topografía precisa.» Véanse n. 13, $\$ 3$ (de 1958) y 53 (de 1975).

66. 1986. «Publio Virgilio Marón: La Eneida» (\$ 8), Biblioteca personal (1988). "Virgilio es nuestro amigo. Cuando Dante Alighieri hace de Virgilio su guía y el personaje más constante de la Comedia, da perdurable forma estética a lo que sentimos y agradecemos todos los hombres."

67. 1986. "Attiglio Momigliano: Ensayo sobre el "Orlando Furioso" (\$ 1 y 3), Biblioteca personal (1988). "He manejado muchas ediciones de la Comedia; estoy seguro de que la mejor es la de Momigliano, que data de 1945. Según se sabe, los comentarios más antiguos fueron de carácter teológico. El siglo XIX indagó las circunstancias biográficas del autor y los ecos de Virgilio y de la Escritura, que hay en el texto. Momigliano, como Carlo Grabher, añade un tercer tipo de comentario, el comentario estético. Ese método es el normal; juzgamos a los libros por la emoción que suscitan, por su belleza, no por razones de orden doctrinal o político.» (\$ 1$)$ «Momigliano ha escrito que Ariosto inspira simpatía, no veneración. Es evidente que al trazar esa línea pensó en Dante Alighieri.» (\$3) 
Los estímulos precisos

Inf. I 1-2: véase n. 10 de junio de 1977.

68. 5-VI-1978. «La inmortalidad» (\$ 18), Borges oral (1979). «Cuando Dante dice: n'el mezzo del cammin de nostra vita, nos recuerda que las Escrituras nos aconsejaban setenta años de vida. Así, cuando había cumplido los treinta y cinco años, tuvo esa visión».

Inf. I 49-60

69. 9-VII-1937. «Un libro sobre Paul Valéry», El Hogar; reed.: Textos cautivos. Trata de la «doble intuición» de las alegorías y los símbolos, y pone como ejemplo: «La hambrienta y flaca loba del primer canto de la Divina Comedia no es la Avaricia: es una loba, y es también la avaricia, como en los sueños» $(\$ 4)$.

70. «H.G. Wells y las parábolas» (\$ 2), Sur, julio de 1937; Discusión (1957). Mismo motivo: «La hambrienta y flaca loba del primer canto de la Divina Comedia no es un emblema o letra de la avaricia: es una loba y es también la avaricia, como en los sueños».

Inf. I 32: véase n. 10, $\$ 51$ y 52 (de junio de 1977).

71. «Inferno, I, 32», Ciclón, La Habana, mayo de 1955; El hacedor (1960). Véanse n. 40 (de 1960), 56 (de 1977) y 72 (de 1986).

72. «Borges, un tejedor de sueños» (entrevista; $\$ 16$ ), La Prensa, Buenos Aires, 3-VIII-1986; Textos recobrados 1956-1986 (2003). La entrevistadora pregunta a Borges si cree en Dios o en la Verdad, y Borges responde: "Yo no sé, sería muy raro que nosotros pudiéramos comprenderla. En un cuento mío, o una especie de cuento, hablo de eso. Yo estaba releyendo la Divina Comedia, y usted recordará que en el Primer Canto, Dante se encuentra con dos o tres animales, y uno de ellos es un leopardo. Luego el editor hace notar que llevaron a Florencia un leopardo en tal fecha, y que Dante habría visto ese leopardo, como todo ciudadano de Florencia, y por eso puso un leopardo en el Primer Canto del Infierno. Entonces, yo imagino que a ese leopardo un sueño le revela que él ha sido creado para que Dante lo vea y lo use en su poema. El leopardo en el sueño entiende eso, pero cuando despierta, naturalmente, ¿Cómo va a entender que él existe para que un hombre escriba un poema? Y luego yo digo que si a Dante le hubiera sido revelado por qué él ha escrito la Comedia, él podría entenderlo como en un sueño, pero al despertar, no. Sería tan complicada la razón, como la otra para el leopardo». Borges se refiere al n. 71 (de 1955). Véanse también n. 40 (de 1960) y 56 (de 1977). 
Inf. I 60: véase n. 11 de 1982.

73. «Nota sobre (hacia) Bernard Shaw» ( $\$ 1$ nota), Sur, junio de 1951; Otras inquisiciones (1952). Acerca del sentido de amica silentia lunae, que en la Eneida y sus imitadores (el Paraíso Perdido de Milton y Dante) significan «el interlunio, la oscuridad». "En la Comedia (Infierno, I, 60; V, 28) tenemos: d'ogni luce muto y dove il sol tace para significar lugares oscuros».

Inf. II 93: véase n. 8 de 1957.

Inf. III 77

74. «El monstruo Aqueronte» (\$ 2), Manual de zoología fantástica (1957); El libro de los seres imaginarios (1967, ambos junto a Margarita Guerrero). "Su nombre retumba en la Eneida, en la Farsalia de Lucano y en las Metamorfosis de Ovidio. Dante lo graba en un verso: Su la trista riviera d'Acheronte.»

Inf. III 124: véase n. 0 de 1949.

Inf. IV 39: véanse n. 0 de 1949 y 7 de abril de 1951.

Inf. IV 86: véase n. 8 de 1957.

75. «Juan Ramón Jiménez» (\$ 2), La Torre, Universidad de Puerto Rico (juliodiciembre de 1957). Sobre la desaparición de la épica, dice Borges: «el poeta ya no es la armada sombra que Dante (mira colui con quella spada in mano) vio en la grave penumbra del primer círculo, sino el hombre sensible que conmemora una intimidad amorosa».

Inf. IV 101: véase n. 7 de abril de 1951.

Inf. IV 106-151: véase n. 10 de junio de 1977.

76. «La pesadilla» ( $\$ 40-44)$, Siete noches (1980). A partir del examen de la visita al nobile castello, se concluye que en el infierno "Ocurren cosas atroces, pero no hay el ambiente de pesadilla que hay en el "noble castillo". Eso lo ofrece Dante, quizá por primera vez en la literatura». Véanse n. 25 (de 1943), 7, \$1 (de abril de 1951), 55 (de 1976) y 62 (de 1984).

Inf. IV, 123: véase n. 7 de abril de 1951.

77. «El arte narrativo y la magia» ( $\$ 4$ nota), Sur, enero de 1932; Discusión (1932). Establece un paralelo entre un pasaje de la novela The life and death of Jason, de William Morris, y el poema dantesco: «Después, como pesaroso del hijo que va a perder, trata de imaginar su futura vida en la selva, entre los quick-eyed centaurs — rasgo que los anima, justificado por su condición famosa de arqueros». Este rasgo descriptivo activa la memoria de Borges, que recuerda el verso del Inf.: «Cesare armato, con li occhi grifagni». 
Inf. v: véase n. 10 de junio de 1977.

Inf. v 129: véase n. 10 de junio de 1977.

78. «Inferno, V, 129», La cifra (1981).

Inf. v 142: véase n. 10 de junio de 1977.

Inf. VI 13-24

79. «El cancerbero» (\$ 1 y 5), Manual de zoología fantástica (1957); El libro de los seres imaginarios (1967, ambos junto a Margarita Guerrero). «Dante le presta caracteres humanos que agravan su índole infernal: barba mugrienta y negra, manos uñosas que desgarran, entre la lluvia, las almas de los réprobos. Muerde, ladra y muestra los dientes.» «El brahamanismo y el budismo ofrecen infiernos de perros, que, a semejanza del Cerbero dantesco, son verdugos de las almas.»

Inf. XII

80. «El centauro" (\$ 6), Manual de zoología fantástica (1957); El libro de los seres imaginarios (1967, ambos junto a Margarita Guerrero). "Quirón memorablemente figura en el canto duodécimo del Infierno, que por consenso general se llama "canto de los Centauros". Véanse a este propósito las finas observaciones de Momigliano, en su edición de 1945.»

Inf. XII 1-30

81. «Sarmiento» ( $\$ 1)$, fechado; La Nación, Buenos Aires, 12-II-1961; Textos recobrados 1956-1986 (2003). Revisión de monstruos híbridos para explicar la «doble visión» de Sarmiento, que oscila entre la «miseria actual de la patria» y su «futura grandeza»; entre los animales mitológicos, menciona al minotauro: «el hombre con cabeza de toro, como Dante lo soñó, a través de unas ambiguas palabras de las Metamorfosis».

82. "El minotauro» (\$ 3), Manual de zoología fantástica (1957); El libro de los seres imaginarios (1967, ambos junto a Margarita Guerrero). "Ovidio, en un pentámetro que trata de ser ingenioso, habla del "hombre mitad toro y toro mitad hombre"; Dante, que conocía las palabras de los antiguos pero no sus monedas y monumentos, imaginó al Minotauro con cabeza de hombre y cuerpo de toro (Infierno, XII, 1-30).»

83. "El laberinto», Atlas (1984). "Éste es el laberinto de Creta cuyo centro fue el Minotauro que Dante imaginó como un toro con cabeza de hombre y en cuya red de piedra se perdieron tantas generaciones.»

Inf. XV 9: véase n. 0 de 1949.

Inf. XVII 127-136: véase n. 10 de junio de 1977.

Inf. XXIV 106-108 
84. "El ave fénix» (\$ 4), Manual de zoología fantástica (1957); El libro de los seres imaginarios (1967, ambos junto a Margarita Guerrero). La Comedia es uno de los lugares de la literatura en los que se menciona al fénix.

Inf. XXV 64: véase n. 0 de 1949.

Inf. XXVI 90-142: véanse n. 1 de marzo de 1948, 5 de agosto de 1948 y 10 de junio de 1977. Véase también n. 13, $\$ 4$ (de 1958).

85. «Historia del tango» (El desafío, $\$ 3$ ), La Nación, Buenos Aires (28-XII1952); Evaristo Carriego. "el hombre siempre es artífice de su propia desdicha, como el Ulises del canto XXVI del Infierno».

Inf. XXXII 24: véase n. 0 de 1949.

Inf. XXXIII 75: véanse n. 4 de mayo de 1948 y 13, $\$ 3$ de 1958.

Purg. I 13: véase n. 10 de junio de 1977.

86. «La metáfora» (\$ 8), La Nación, Buenos Aires (9-XI-1952); Historia de la eternidad (ed. 1953). Examina «el curioso verso en que Dante (Purgatorio, I, 13), para definir el cielo oriental invoca una piedra oriental, una piedra límpida en cuyo nombre está, por venturoso azar, el Oriente: Dolce color d'oriental zaffiro es, más allá de cualquier duda, admirable; no así el de Góngora (Soledad, I, 6): En campos de zafiros pace estrellas que es, si no me equivoco, una mera grosería, un mero énfasis». En nota, remite a Éxodo 24,10 .

Purg. III 34: véase n. 0 de 1949.

Purg. V 85-129

87. «Poema conjetural», fechado en 1943; La Nación, Buenos Aires (4-VII1943); El otro, el mismo (1969).

88. "Literatura alemana» (El Muspilli, $\$ 1)$, Antiguas literaturas germánicas (1951, junto a Delia Ingenieros); Literaturas germánicas medievales (1966, junto a María Esther Vázquez). «En el canto quinto del Purgatorio, el alma de Buonconte da Montefeltro, a quien acaso Dante mató en la batalla de Campaldino, refiere a éste uno de sus duelos. El ángel vence y el demonio, desesperado, ultraja el cadáver, arrojándolo a un río.»

Purg. VI 58: véase n. 0 de 1949.

Purg. VI 112

89. "Destino escandinavo" (\$ 1), Sur, enero-febrero de 1953; Borges en Sur (1999). Se examina el interés del destino individual y el destino de las naciones, y se cita como ejemplo este verso, que prueba «el patetismo de lo genérico». 
Purg. XI 100-102: véanse n. 5 de agosto de 1948 y 7 de abril de 1951.

Purg. XXIX: véase n. 6 de octubre de 1948.

Purg. XXIX 106-129: véase n. 6, \$4, de octubre de 1948.

90. "El grifo», Manual de zoología fantástica (1957); El libro de los seres imaginarios (1967, ambos junto a Margarita Guerrero). "En el canto veintinueve del Purgatorio, Dante sueña con un carro triunfal tirado por un Grifo; la parte de águila es de oro, la de león es blanca, mezclada con bermejo, por significar, según los comentadores, la naturaleza humana de Cristo (Blanco mezclado con bermejo, da el color de la carne.).» En nota, establece un paralelo con los colores del amado en el Cantar de los cantares, 5,10-11.

Purg. XXX 51: véase n. 8 de 1957.

Purg. XXXI 121: véase n. 6 de octubre de 1948.

Par. IV 49: véase n. 0 de 1949.

Par. X: véase n. 8 de 1957.

Par. XVII 23-24: véase n. 10 de junio de 1977.

Par. XVIII: véase n. 2 de marzo de 1948.

Par. XIX 11: véase n. 2 de marzo de 1948.

Par. XXI 121-122

91. «La otra muerte» (\$ 14), La Nación (1949); El Aleph (1949). El estímulo para componer el cuento fueron los versos de la Comedia en los que un personaje se identifica a la vez como Pedro Damián y Pedro Pecador. Borges acude al tratato De omnipotentia de Pier Damiani para resolver el problema de su identidad. También hay una referencia a "Pietro Damiano" en "Nota para un cuento fantástico» (La cifra, 1981), donde se habla del arte «de modificar el pasado» $(\$ 1)$.

Par. XXVI 139-142

92. «Un diálogo anglosajón del siglo XI» (nota, $\$ 5$ y 6), Breve antología anglosajona (1978, junto a María Kodama). Polémica medieval sobre la estancia de Adán en el Paraíso: "Dante (Paradiso, XXVI, 139-142) la limita a siete horas». A continuación, añade una cita del Talmud procedente de las notas de Longfellow «a su versión inglesa de la Comedia, publicada en 1867» (para Longfellow, véanse n. 13, $\$ 2$ (de 1958), 46 (de 1967) y 60 (de 1978).

Par. XXVII 82-83: véase n. 5 de agosto de 1948.

Par. XXX 118: véase n. 12 de 1982.

Par. XXXI: véase n. 12 de 1982.

Par. XXXI 108

93. «Paradiso, XXXI, 108», Sur, noviembre-diciembre de 1954; El hacedor (1960). 
Par. XXXIII 115-117

94. «Una vindicación de la cábala» (\$ 5), fechado en 1931; Discusión (1932). Acerca de la representación de las tres personas de la Trinidad, Borges escribe: «Dante las quiso figurar con el signo de una reverberación de círculos diáfanos, de diverso color».

95. "Historia de la eternidad» (II, $\$ 3$ ), fechado en 1953; Historia de la eternidad (1953). Acerca de la Trinidad: "Dante las quiso denotar con el signo de una superposición de círculos diáfanos, de diverso color».

\section{Comentaristas citados}

Alighieri, Jacopo: 13, $\$ 4$ (de 1958).

Andreoli, Raffaele: 5 (agosto de 1948).

Anónimo Florentino: 5 (agosto de 1948).

Bianchi, Enrico: 4 (mayo de 1948).

Buti, Francesco da: 0 (1949), 6 (diciembre de 1948).

Carlyle, John Aitken: 13, $\$ 5$ (1958), 14, IV, $\$ 8$ (1970), 10 (junio de 1977).

Casini, Tommaso: 2 (marzo de 1948), 4 (mayo de 1948), 5 (agosto de 1948), 12 (1982).

Claudel, Paul: 0 (1949), 14, IV, $\$ 8$ (1970), 10 (junio de 1977).

Croce, Benedetto: 4 (mayo de 1948), 7 (abril de 1951).

D'Ovidio, Francesco: 4 (mayo de 1948).

Dante, Iacopo di: 0 (1949).

Dante, Pietro di: 6 (diciembre de 1948).

De Sanctis, Francesco: 4 (mayo de 1948), 12 (1982).

Dridon: 6 (diciembre de 1948).

Friedrich, Hugo: 5 (agosto de 1948).

Grabher, Carlo: 13, \$5 (1958), 10 (junio de 1977), 15 (agosto de 1979), 67 (1986). Imola, Benvenuto da: 6 (diciembre de 1948).

Imola, Rambaldi da: 4 (mayo de 1948).

Lana, Iacopo della: 0 (1949).

Lombardi, Bonaventura: 6 (diciembre de 1948).

Longfellow, Henry Wadsworth: 13, $\$ 2$ (1958), 46 (1967), 60 (1978), 92 (1982). Momigliano, Attilio: 7 (abril de 1951), 80 (1957), 13, $\$ 5$ (1958), 10 (junio de 1977), 15 (agosto de 1979), 67 (1986).

Pietrobono, Luigi: 4 (mayo de 1948), 5 (agosto de 1948), 6 (diciembre de 1948), 12 (1982).

Provenzal, Dino: 45 (1966).

Ruegg, August: 5 (agosto de 1948).

Steiner, Carlo: 5 (agosto de 1948), 6 (diciembre de 1948), 10 (junio de 1977).

Tommaseo, Niccolò: 5 (agosto de 1948), 6 (diciembre de 1948).

Torraca, Francesco: 4 (mayo de 1948), 6 (diciembre de 1948), 7 (abril de 1951), 12 (1982).

Vitali, Guido: 2 (marzo de 1948), 4 (mayo de 1948), 6 (diciembre de 1948), 7 (abril de 1951), 12 (1982). 